\title{
Scientia y sapientia en De Trinitate XII: San Agustín y las formas de la racionalidad
}

\author{
Manfred Svensson \\ INSTITUTO DE FILOSOFÍA \\ UNIVERSIDAD DE LOS ANDES
}

\section{Introducción}

En el segundo libro de su Suma Teológica Alberto Magno escribe que Aristóteles y san Agustín dan distinto significado al término scientia: «Aristóteles habla de la scientia para referirse a lo que es a partir de lo primero, verdadero e inmediato. Pero Agustín no habla así acerca de la scientia, sino que usa este término para referirse al saber que es a partir de conjeturas de los hombres, para lo que pertenece al gobierno de la vida humana»'. Si estas palabras de Alberto Magno son en alguna medida acertadas respecto de Agustín, deberían modificar en algunos sentidos importantes nuestra visión de la noción de sabiduría sostenida por éste. Pues Alberto está atribuyendo aquí a Agustín el haber tenido una concepción de racionalidad específicamente práctica, tanto por lo que respecta a su origen «a partir de conjeturas de los hombres» como por lo que respecta a su fin, «para lo que pertenece al gobierno de la vida humana»; y tal saber es además contrastado con la epistêmê aristotélica, con lo cual su carácter práctico parece adquirir un perfil más nítido aún. ¿Es sostenible esto como lectura de san Agustín?

Si existe un status quaestionis, la balanza parece inclinarse más bien en la dirección contraria. Pues sapientia, no scientia, suele ser considerado como el término decisivo para exponer aquello que interesa a Agustín². Incluso

1 Alberto Magno, S. Th. II, tract. XV, qu. 93, m.4, ad 2. Aristoteles loquitur de scientia secundum quod est ex primis, veris, et immediatis: et hoc modo non loquitur Augustinus de scientia, sed secundum quos est ex conjecturis humanorum ad gubernationem vitae humanae pertinentiam.

2 Como ejemplo paradigmático puede citarse R. HoLTE, Beatitudo och sapientia (Almqvist \& Wiksells, Uppsala, 1958). 
la idea de una distinción entre saber práctico y saber teórico es una nota específica de la tradición aristotélica que parecería extraño encontrar en la obra de este platónico cristiano. Y cuando se atiende a la distinción entre sapientia y scientia que Agustín desarrolla en De Trinitate, suele casi invariablemente entenderse la scientia como el saber teórico ${ }^{3}$, de modo que se concede que hay una distinción entre formas de conocimiento, incluso comparable a una distinción de Aristóteles, pero una distinta de la aludida por Alberto Magno: se trataría sólo de una distinción entre distintos tipos de conocimiento teórico, sophia y epistêmê.

De este modo, no es extraño que Agustín haya sido una figura en gran medida ausente en la rehabilitación de la filosofía práctica que tuvo lugar durante el siglo XX. Pues tal proyecto se apoyó en parte en desarrollos filosóficos contemporáneos, pero muy decisivamente también en una recuperación de la filosofía práctica de Aristóteles, en la que se podía encontrar tanto la supremacía de un género de vida teórico, como el desarrollo de una racionalidad específicamente práctica, una racionalidad que en conjunción con el recto deseo es capaz de mover al hombre, y que se distingue de la racionalidad teórica tanto por su objeto como por su finalidad y método. El contraste con la posición generalmente atribuida a Agustín salta sobre todo a la vista en Hannah Arendt, quien ha visto en el cristianismo -y remite para ello a Agustín como caso ejemplar- una destrucción de la vida política, la cual ya no sería vista como un género de vida libre, y en ese sentido equiparable al género de vida contemplativo, sino como un género de vida bajo el peso de la necesidad, comparable en ese sentido a lo que Aristóteles piensa sobre la vida del comerciante. Si antes había búsqueda de la eternidad en la vida teórica y búsqueda de inmortalidad en la vida política, el cristianismo dejaría sólo la primera en pie, reduciendo la vida política a un elemento cualquiera del campo de lo perecible ${ }^{4}$.

San Agustín parece así ser el aliado menos probable para la rehabilitación requerida: por una parte hay que considerar que no recibe nada de Aristóteles, y por otra que si bien es heredero de Platón, no llega a él rasgo alguno del pensamiento político de éste: parece seguir a Platón en la salida de la caverna, pero no en la vuelta a la misma. A pesar de estos indicios en sentido contrario, la tesis del presente artículo es que si

\footnotetext{
3 A modo de ejemplo pueden citarse las obras de J. Hessen y R. NASH que discutimos en la cuarta sección del presente artículo.

4 H. Arend, The Human Condition (Chicago, 1958) 13-21 y 318-319.
} 
desarrollamos adecuadamente aquello que Alberto Magno parece haber visto, la situación cambia de modo significativo. Esto es, sostenemos que Agustín desarrolló una original concepción de la racionalidad práctica. No una posición a medias, pero sí una posición que en algunos sentidos importantes puede ser calificada de intermedia, entre Platón y Aristóteles. $\mathrm{Y}$ en este desarrollo aspectos centrales de la fe cristiana -como el énfasis agustiniano en la severidad de la caída, pero no sólo eso- desempeñaron un papel decisivo. Para mostrar esto atenderé en primer lugar, de modo breve, a la pregunta por los géneros de vida, que servirá para explicar el modo en que entiendo la posición de Agustín como intermedia. Tras un breve excurso dedicado a su evolución intelectual en esta materia, me dirigiré a las distintas formas de racionalidad, scientia y sapientia, cuestión a la que dedicaré la mayor parte del presente texto. Finalmente, planteo algunas cuestiones respecto del papel que esta distinción desempeña en el De Trinitate, única obra en que san Agustín la desarrolla.

\section{Modos de vida y formas de racionalidad}

Existe en distintos autores una fácilmente constatable y esperable correspondencia entre géneros de vida y formas de la racionalidad. Con una concepción unitaria de sabiduría en Platón -manifiesta, por ejemplo, en el hecho de que no acuñe un término técnico para el conocimiento práctico, coincide la figura del rey-filósofo. En contraste con eso tenemos en Aristóteles una distinción entre distintas formas de conocimiento, un conocimiento teórico (sophia) y otro práctico (phronêsis), distinción con la que se corresponde una distinción entre la vida filosófica por una parte y la vida política por otra ${ }^{5}$. Pero más que sobre una distinción debemos hablar en el caso de Aristóteles de una separación. No, desde luego, en el sentido de que su ideal de hombre sea alguien que sólo tiene una de estas virtudes intelectuales. Pero sí en el sentido de que considera posible tener la una sin la otra: hay quienes investigan cosas maravillosas y divinas pero que, sin embargo, no saben lo que les conviene, no buscan los bienes humanos ${ }^{6}$. Son sophoi sin phronêsis. El mundo antiguo nos ofrece pues o bien una estricta unidad o bien dos formas de conocimiento y de vida en principio separables. ¿Hay algo que decir sobre Agustín en torno a esta cuestión? Los escritos tempranos presentan al menos una constante tematización

\footnotetext{
5 Véase sobre todo EN VI, 7 y 12 para los géneros de conocimiento y X 6-8 para los géneros de vida.

6 EN VI 7,1141b 3-8.
} 
de la filosofía como género de vida. Especialmente se suele notar en este sentido la importancia de los prólogos del de beata vita y el contra academicos, verdaderos protrépticos por los que Agustín invita a sus previos mecenas al nuevo género de vida que él ha encontrado. Pero en estos textos sólo la filosofía, no la política, es tratada como género de vida. En ese sentido es más significativo un texto escritos unos meses más tarde, la última sección del de ordine, que no ha recibido la atención merecida. La mayor parte del segundo libro de esta obra se ocupa de un ascenso a través de distintas disciplinas, las siete artes que más tarde compondrían el trivium y el quadrivium, ascenso que por lo demás recuerda el del libro VII de La República de Platón. Dicho ascenso culmina no con una mención de Platón, pero sí de Pitágoras, el cual es elogiado por Agustín por haber introducido a sus alumnos, como último paso, en el arte de gobernar. Esto es, por haberlos introducido en tal arte recién tras haberlos vuelto estables mediante las ciencias. Entonces pueden gobernar, al ser «ya doctos, ya perfectos, ya sabios, ya felices»7. No hay en este texto mención de Platón, pero el tipo de actor que Agustín tiene en mente indudablemente es comparable a una figura como el rey-filósofo, cuya formación no es específica o exclusivamente práctica: su formación en las ciencias lo ha conducido al tipo de felicidad y perfección que lo mantendrá firme en medio del inestable oleaje de la vida política.

¿Qué ocurre con esta tesis platónica en la obra de madurez de Agustín? Para constatar su desmantelamiento podría bastar con atender a una mención tardía de Pitágoras. Al iniciar el libro VIII de La Ciudad de Dios, esto es, en el año 417 (20 años después del de ordine), Agustín escribe una programática síntesis de la historia de la filosofía, pero mencionando a Pitágoras como representante de un género de vida puramente teórico, en contraste con Sócrates como representante de la filosofía moral: «Sócrates es recordado por haber sobresalido en la acción, Pitágoras en cambio por esforzarse con todos sus recursos en la inteligencia contemplativa» ${ }^{8}$. La figura de Pitágoras ya no es ocasión para invocar un género de vida que una la política y la filosofía, sino una existencia puramente contemplativa. El ideal de Agustín aquí sigue siendo el de una unión de ambos aspectos -según este pasaje, Platón perfeccionó la filosofía precisamente en la medida en que unió las fortalezas de Pitágoras y Sócrates-, pero

ord. II, 20, 54. Cito las obras de san Agustín conforme a las últimas ediciones de CCL

y CSEL y sigo las abreviaciones hoy casi canónicas del Augustinus-Lexikon.

8 civ. VIII, 4. 
no ya una unidad indiferenciada, sino una unidad en que ya se ha concebido la posibilidad de que sus elementos se realicen, como en los casos pitagórico y socrático, por separado. Y ya ello parece constituir un serio obstáculo a la interpretación de Arendt: precisamente en la madurez de Agustín, cuando más hondo es el impacto que el cristianismo deja en su obra, concibe la vida política y la vida filosófica como géneros de vida con méritos propios, sin fundirlos ni ver el valor de uno meramente en estar al servicio del otro.

La obra de madurez de Agustín contiene también algunos otros elementos que confirman su evolución desde la temprana concepción platónica a la más compleja versión posterior. Resulta en este sentido llamativo que un platónico cristiano, como es san Agustín, no se entusiasme con la figura de los emperadores cristianos como reyes-filósofos?. Tales figuras son moneda corriente en el platonismo cristiano, por ejemplo en la consideración (siguiendo a Filón) de Moisés como legislador, profeta y filósofo. Son corrientes también en el platonismo político islámico, en la fusión del profeta con el rey-filósofo ${ }^{10}$. Pero san Agustín constituye una excepción, pues en su obra madura no encontramos ese tipo de figuras unitarias. En lugar de eso tenemos ahí una recurrente discusión de los géneros de vida a partir de parejas de personajes bíblicos ${ }^{11}$. Particularmente significativo es, además, el modo en que se une la discusión de los géneros de vida a las virtudes teologales. Ambos géneros de vida aparecen vinculados al amor, con la contemplación caracterizada como amor veritatis, y la acción como officium caritatis $^{12}$; pero esta diferencia entre ambas es completada por la identificación de una con la esperanza y la otra con la fe. Fundamental es en ese sentido la afirmación paulina de II Cor 5,7: «andamos por fe, no por visión (non per speciem)», que unida a afirmaciones sobre la fe que obra por el amor (Gal 5,6b) o el justo que vive por la fe (Hab 2,4 = Rom

9 De hecho, cuando discute sobre estos emperadores, hay un marcado contraste con el pasaje del de ordine que hemos citado antes, ya que en lugar de describirlos como iam beati, los emperadores cristianos aparecen descritos como felices interim spe. Cfr. civ. V, 24.

10 Véase Clemente de Alejandría, strom. I, 24, 158-25, 166 y Averroes, Comentario a la República de Platón II, 1.

11 Véase los sermones 103, 104, 169, 17; 179 y 255 para María y Marta, c. Faust. XXII, 52-58 para Lea y Raquel, y Io. ev. tr. 124 para Juan y Pedro.

12 civ. XIX, 19. 
$1,17)^{13}$, liga por una parte la vida práctica a la fe, y por otra parte la vida contemplativa con la esperanza (species-spes), pues en esta vida sólo «conocemos en parte» (I Cor 13,9) ${ }^{14}$.

Por lo pronto basten estos indicios, así como el tomar nota de su origen paulino. Pues el paso que aquí nos interesa es el que sigue. Si es posible esperar en Agustín, tal como en Platón y Aristóteles, una correspondencia entre géneros de vida y formas de conocimiento, entonces también en lo que respecta a las formas de conocimiento podríamos esperar una evolución desde una inicial concepción unitaria de la sabiduría a una posterior diferenciación, paralela a la que aquí hemos esbozado respecto de los géneros de vida. De haberla, su obra madura nos tendrá que ofrecer observaciones sobre las formas de conocimiento aún insuficientemente exploradas.

\section{Partición del alma y bipartición de la racionalidad: la evolución de Agustin}

Es hoy un elemento estándar de las investigaciones sobre Agustín el atender a su evolución intelectual. Y aunque no se adhiera a las corrientes más radicales de esta tendencia ${ }^{15}$, basta leer las Retractaciones del mismo Agustín para ver lo mucho que él mismo considera haber cambiado, lo que lo lleva a rogar a sus lectores que progresen junto con él ${ }^{16}$. Pero esto constituye una invitación a una ardua tarea, pues precisamente algunos de los cambios más significativos en su pensamiento no están consignados por él en las Retractaciones, obra concentrada en retractarse de aquellos elementos que pudieran ser punto de apoyo para sus adversarios pelagianos. Uno de esos cambios no consignados es el que nos interesa aquí.

Tal como en sus antecesores griegos, en Agustín la discusión sobre las formas de conocimiento se relaciona con una partición del alma. En un escrito temprano, el de Genesi adversus Manichaeos, ella es dividida simplemente en una parte racional y una parte irracional. Pero las cosas se complican. Pues esta división entronca en Agustín con un tipo de interpretación alegórica de la diferenciación sexual que se remonta al menos

13 perf. iust. 8, 18.

14 Un texto que Agustín, con el paso de los años, citará de modo creciente. Cfr. cons. ev. I, 5,8 .

15 Su principal representante y popularizador es K. FLASCH, Augustin, Einfübrung in sein Denken (Reclam, Stuttgart, 1994).

16 praed. sanct. $4,8$. 
hasta Filón de Alejandría. Éste había visto a la mujer como alegoría de los aspectos sensitivos del ser humano, y al hombre como representante de los aspectos racionales ${ }^{17}$. Muy significativamente, Agustín ni siquiera en sus comienzos sigue esta interpretación, la cual conocía sin lugar a dudas al menos por Ambrosio, quien sí la adopta ${ }^{18}$. Más cerca de Agustín parece encontrarse Orígenes -cuya versión muy probablemente Agustín conocía también-, quien entiende al hombre como imagen del spiritus y a la mujer como imagen de la anima ${ }^{19}$. Esto es más cercano a Agustín en el sentido de que ni siquiera en su más temprana exposición del Génesis pone Agustín a la mujer como imagen del mero sentido, sino como appetitus animae, affectus $\mathrm{O}$ animalis par $^{20}$. Es ésta la parte del hombre tentada por la serpiente, y el pecado consiste básicamente en que la razón, de la cual es imagen Adán, preste su consentimiento a la cupiditas nacida de la sugerencia hecha por la serpiente.

Sobre este esquema de un alma bipartita, con una parte racional y una parte animal o apetitiva, además de un tentador externo, descansa pues una estructura de suggestio-cupiditas-consensio, estructura que opera como herramienta para explicar la tentación y la caída en esta temprana obra. Y a la existencia de una indivisa parte racional corresponde que en toda la obra temprana de Agustín exista una sola forma de sabiduría: en contraste con el tardío uso de scientia y sapientia, aquí encontramos sólo una omniabarcante sapientia. Pero precisamente el hecho de que se esté intentando explicar el proceso de tentación puede ser uno de los factores que llevaría a Agustín a realizar algunas significativas modificaciones en este esquema. En concreto porque la cupiditas aquí descrita no es un deseo racional, sino un apetito animal, y esto parece impedir una descripción de la tentación y del pecado en todos sus grados. Pues pecado habría sólo por el consentimiento de la razón, pero al haberlo se produciría también de inmediato, de no haber impedimento externo, la acción. Al introducirse la razón, se introduce el consentimiento; el deleite previo, en cambio, no es de la razón, sino de una cupiditas identificada sin más con la parte animal del hombre. La posibilidad

\footnotetext{
17 Cf. Filón de Alejandría De opificio mundi 59, 165 y Quaestiones et solutiones in Genesin I, 47.

18 San Ambrosio De paradiso II, 11 y XV, 73.

19 Orígenes Hom. Gn. I, 15.

20 Gn. adv. Man. II, 11, 15; II, 14, 20-21 y II, 18, 27.
} 
de un pecado que no acabe en una obra externa, que sea por ejemplo sólo un deleitarse en la idea de pecar, no tiene aquí cabida ${ }^{21}$.

El pensamiento de Agustín como ha sido presentado hasta aquí representa una constante en sus primeros escritos. Al menos hasta el año 404-405 se puede trazar huellas de esta concepción. Pero ya desde antes se había iniciado en su mente un proceso de revisión que terminaría no sólo en una visión muchísimo más sofisticada de la tentación, sino gracias a ello también en una original concepción de la racionalidad contemplativa y la práctica. Antes de entrar en algunos detalles de tal evolución, precisemos una vez más la causa de la misma. No se trata para él de buscar una alegoría que haga más justicia a la mujer. Ello no es necesario, pues tanto en el Comentario al Génesis Contra los Maniqueos como en el más tardío Comentario Literal al Génesis está fuera de duda que aquello por lo que hombre y mujer son imagen de Dios, su intelecto, es a la vez la parte de ellos en la que no hay diferenciación sexual ${ }^{22}$. Pero es típica de la exégesis agustiniana la siguiente (a veces implícita) pregunta. ¿Por qué menciona entonces el texto bíblico la diferenciación sexual, si ésta no es relevante para nuestra vida espiritual? Semejante mención de cosas «irrelevantes» en el texto bíblico son las que justificarían una interpretación alegórica del mismo ${ }^{23}$. Al incluir en la narrativa la distinción entre hombre y mujer, el apóstol Pablo debe pues estar intentando decirnos algo sobre una diferenciación no entre el hombre y la mujer, sino sobre una diferenciación existente dentro de cada uno de nosotros, lo cual, en contraste con la diferenciación sexual, sería suficientemente relevante como para ser incluido en el relato bíblico. ¿Qué diferenciación? La respuesta a esa pregunta es lo que en parte mueve a la evolución de Agustín que aquí comentamos: la búsqueda de una interpretación alegórica que haga justicia a la compleja psicología humana.

21 Compárese los pasajes citados de Gn. adv. Man. con trin. XII, 12, 17-18.

22 trin. XII, 7, 12. ubi sexus nullus est. Cfr. Gn. litt. III, 22, 34.

23 Cuando san Agustín da su regla general para distinguir locuciones figuradas de literales en doctr. chr. III, 10, 14, lo requerido es leer como literal todo lo que no atente contra la caridad. Lo que encontramos aquí es una singular variante de esa norma: tal como la Biblia no puede tener nada contrario al amor, es también absurdo pensar que tenga algo superfluo. Lo que parezca superfluo, invita pues a la alegoría. Cfr. trin. XII, 7, 11. manifestum est quid Apostolus significare voluerit; ideo figurate ac mystice, quia de velando muliebri capite loquebatur, quod nisi ad aliquod secretum sacramenti referatur, inane remanebit. 
La existencia de esta evolución se puede constatar en primer lugar de modo muy sencillo a nivel de la pregunta por la división del alma. Mientras que en el temprano Comentario al Génesis Contra los Maniqueos encontramos el alma dividida simplemente en una parte racional y una parte irracional, representadas por Adán y Eva, la misma pareja del paraíso será mencionada en el más maduro Comentario Literal al Génesis no como imagen de lo racional y lo irracional, sino de dos distintos campos de actividad racional, una «verdad de la eterna contemplación» y una «administración de las cosas temporales ${ }^{24}$. El alma simplemente dividida en su parte racional y su parte irracional ha sido reemplazada por un alma en que también la parte racional es subdividida. Tal como nos hemos apoyado en Alberto Magno como alguien que prestó atención al sentido específico de scientia en la producción madura de Agustín, cabe mencionar a Tomás de Aquino como alguien singularmente atento a la evolución intelectual que hemos descrito aquí. Pues en respuesta a una objeción en De Veritate q. 15 hace notar que las tres etapas de la tentación son descritas de modo diverso en el temprano comentario al Génesis y en el posterior De Trinitate: «En De Trinitate XII atribuye, en efecto, la serpiente a la sensualidad y la mujer a una razón inferior, mientras que en el libro contra los maniqueos había atribuido la serpiente al sentido y la mujer a la concupiscencia o sensualidad, y al hombre la razón» ${ }^{25}$. La importancia de tal evolución para la imagen agustiniana del hombre no ha sido adecuadamente tratada por la investigación moderna sobre san Agustín, la que en este punto parece encontrarse detrás de los grandes medievales.

En efecto, al escribir el libro XII del De Trinitate Agustín tomará con plena conciencia distancia de la tradición anterior y de su propia posición más temprana, señalando que la mujer tiene que ser imagen de algo espe-

24 Gn. litt. III, 22, 34. licet enim subtilissime disseratur ipsam mentem hominis, in qua factus est ad imaginem dei, quandam scilicet rationalem vitam, distribui in aeternae contemplationis veritatem et in rerum temporalium administrationem, atque ita fieri quasi masculum et feminam illa parte consulente, hac obtemperante: in hac tamen distributione non recte dicitur imago dei, nisi illud, quod inhaeret contemplandae incommutabili veritati.

25 Tomás de Aquino, De veritate, q. 15 a. 4 ad 7. Ad septimum dicendum, quod Augustinus in Lib. contra Manichaeum non eodem modo exponit illa tria, sicut in libro de Trinit. In XII de Trinitate enim serpentem attribuit sensualitati, mulierem inferiori rationi, virum superiori; sed in Lib. contra Manichaeum, serpentem sensui, mulierem concupiscentiae sive sensualitati, virum rationi. 
cíficamente humano ${ }^{26}$. Se encuentra así asentada la división no sólo entre una parte racional y otra irracional, sino una división dentro de lo racional, en dos partes que tradicionalmente han sido designadas como ratio inferior y ratio superior, cuyas respectivas excelencias Agustín llama scientia y sapientia ${ }^{27}$. Tal división recuerda sin duda la división aristotélica entre un epistêmonikon y un logistikon de la parte racional del alma, de los cuales son excelencia la sophia y la phronêsis ${ }^{28}$. En efecto, con esto están sentadas las bases para una aproximación a la posición de Aristóteles (aunque no la conociera), pero con elementos de una significativa originalidad agustiniana.

\section{Scientia y sapientia}

El libro XII del De Trinitate es de toda la producción agustiniana el principal texto para nuestro problema. Hasta ahora, sin embargo, no se ha acostumbrado interpretar este texto del modo que aquí lo haremos. Al menos una importante razón para una lectura distinta de la nuestra es de fácil identificación: en las traducciones del De Trinitate a lenguas modernas scientia se encuentra generalmente traducido mediante términos que, como science o ciencia, refieren a la ciencia natural. Incluso cuando una lengua moderna no tiene esa connotación restringida -como en el caso de Wissenschaft en alemán-, se trata en cualquier caso de términos que hacen referencia a un saber que no es primariamente directivo, sino descriptivo. Así, se ha asumido que si hay en el texto de Agustín una distinción entre formas de conocimiento, habrá que entenderla como una distinción -por continuar la comparación con la terminología aristotélica- entre epistêmê y sophia, dos formas de conocimiento teórico, o a lo sumo la segunda con un componente práctico ${ }^{29}$. Pero -y ésta es la primera objeción que se puede levantar

26 trin. XII, 13, 20.

27 No está de más notar que las expresiones ratio inferior y ratio superior no se encuentran en Agustín, quien tiende a optar por términos que acentúen menos la distinción. El origen de esta terminología, en el siglo XIII ya clásica, parece remontarse no más allá de Lombardo.

28 Véase EN VI 2, 1138b 35-1139a 15 y VI 12, 1143b 16.

29 Un antiguo difusor de esta concepción es J. HessEN, Die Begründung der Erkenntnis nach dem heiligen Augustinus (Münster, 1916) 38-47. El mismo género de error, pero convirtiendo la scientia en conocimiento técnico, se encuentra en R. NASH, The Light of the Mind: St. Augustine's Theory of Knowledge (Lexington, 1969) 8: «Scientia enables man to harvest better crops, construct better buildings, or wage war more effectively». Desde luego hay quienes en contraste con estos autores han referido correctamente el sentido 
contra dicha tradicional lectura- scientia debería ser traducido simplemente como forma sustantiva de scire: conocimiento ${ }^{30}$. ¿Qué conocimiento? La distinción entre scientia y sapientia se apoya en un conjunto de textos bíblicos, a los cuales hay que acudir para comprender el significado dado por Agustín a los términos. «Algunos han recibido del Espíritu un sermo scientiae, otros han recibido un sermo sapientiae conforme al mismo Espíritu» (I Cor 12,8). La distinción entre dos formas de racionalidad cree pues Agustín encontrarla en san Pablo. Pero Pablo, según confiesa el propio san Agustín, sólo distingue, sin decirnos nada sobre qué es lo que ha distinguido, en qué consisten dichas distintas formas de conocimiento. Así, es sólo tras larga búsqueda, afirma el hiponense, que ha encontrado el texto bíblico que daría contenido a dicha distinción. Se trata de Job 28,28, que en la traducción latina que usa san Agustín dice «He aquí que la piedad es sapientia y evitar el mal es scientia». Respecto de las implicaciones de este vínculo entre pietas y sapientia se podría decir mucho ${ }^{31}$, pero por ahora baste con notar el comentario de Agustín al texto de Job en lo que se refiere a la scientia: «Job dice que el abstenerse del mal corresponde a la scientia, lo cual ciertamente se relaciona con las cosas temporales, pues temporalmente estamos entre los males, de los cuales tenemos que abstenernos para llegar a los bienes eternos $\rangle^{32}$. No son, pues, cualesquiera cosas temporales las que son objeto de la scientia. Ésta es entendida por Agustín como un conocimiento práctico -ni técnico, ni científico, ni contemplativo ${ }^{33}$-, indispensable para lidiar con

de scientia y sapientia, pero en dichos casos sin notar la originalidad de la posición que están refiriendo, ni desarrollar las relaciones entre ambas formas de conocimiento.

30 Esto es evidente no sólo por los motivos de fondo que a continuación exponemos, sino también a la luz de la sola terminología usada en trin. XII, 14, 22. Ahí san Agustín dice que Pablo frecuentemente habla de la scientia, y cita como prueba I Cor 13,12 «ahora conozco (scio) en parte», donde Pablo en realidad sólo usa la forma verbal, y no el sustantivo scientia. Este detalle es pasado por alto por la totalidad de la literatura secundaria al respecto. Por lo demás, si leemos scientia como conocimiento, hacemos justicia al hecho de que el término usado por Pablo es gnôsis y no epistêmê. Dicho punto es adecuadamente notado por M. MaureIRA, «Scientia y Sapientia. Anotaciones Conceptuales al Agustino De Trinitate», Diadokhe 9 (2006) 47.

31 Véase, por ejemplo, la forma en que el libro XIV del De Trinitate vincula la sabiduría con el culto.

32 trin. XII, 14, 22.

33 La descripción que hemos hecho aquí de la scientia sólo la defendemos para aquellos pasajes en los que aparece como contraparte de la sapientia. En el mismo libro XII san Agustín ocupa en dos ocasiones el término scientia con un sentido distinto: al final de XII, 7, 10 designa el conocimiento que tiene el mismo Dios, y en XII, 14, 
los males a los que necesariamente nos enfrentamos en esta vida ${ }^{34}$. Si cabe una comparación de esta pareja agustiniana de formas de conocimiento con una equivalencia aristotélica, no será pues epistêmê y sophia, sino phronêsis y sophia. En efecto, scientia es un término que en De Trinitate XII no cabe ni siquiera comprender como filosofía práctica (que puede ser prescindible para la acción), sino que es inequívocamente presentada como el conocimiento práctico indispensable, que es parte integradora de la acción, por lo que Agustín también designa ocasionalmente esta scientia con términos como usus rationalis, scientia actionis o activa scientia ${ }^{35}$.

¿Pero qué tanta es la cercanía a una posición como la aristotélica? En una primera lectura, enorme. Hay textos en los que da la impresión de haber entre scientia y sapientia una separación tan marcada como entre phronêsis y sophia aristotélicas, y basada tal como en Aristóteles en la naturaleza radicalmente divergente de sus respectivos objetos: «La acción, por la que usamos las cosas temporales, se diferencia (distat) de la contemplación de las cosas eternas; y ésta corresponde a la sapientia, aquélla a la scientias ${ }^{36}$. Esto es incluso enfatizado por Agustín mostrando una forma de conocimiento como discursiva y la otra como intelectual: «La correcta distinción entre sapientia y scientia es que el conocimiento intelectual de las cosas eternas corresponde a la sapientia, a la scientia en cambio el conocimiento racional de las cosas temporales» ${ }^{37}$. A la luz de tal pasaje Gilson ha escrito que «scientia y sapientia se contraponen punto por punto»" ${ }^{38}$, lo cual con toda razón podría decirse de sus equivalentes aristotélicos. Incluso ahí donde Agustín modera esto, parece hacerlo de un modo aristotélico. Así, por ejemplo, cuando se abstiene de hablar propiamente de partes de la razón, indicando que se trata de una distinción propter officia ${ }^{39}$.

22 san Agustín concede que hay textos bíblicos donde scire -forma verbal de scientia - refiere al conocimiento que tenemos o tendremos de Dios. En ese caso, precisa ahí mismo, scientia es por supuesto sinónimo de sapientia, y no parte del binomio agustiniano scientia-sapientia que aquí exploramos.

34 trin. XII, 13, 21. in usum mutabilium corporaliumque rerum sine quo haec vita non agitur.

35 trin. XIII, 1, 4, XII, 12, 17 y XIII, 20, 25, respectivamente.

36 trin. XII, 14, 22.

37 trin. XII, 15, 25.

38 É. GILson, Introduction a l'etude de Saint Augustin (Vrin, Paris, $\left.{ }^{3} 1943\right)$ 147-148.

39 De modo similar Aristóteles habla de una distinción kata dynameis en an. III 10, 433b 1-2. Este es el único punto en que no sólo hay coincidencia entre ambos, sino además una posible influencia indirecta de Aristóteles sobre Agustín. Esto, según mi conje- 
Pero el tipo de unidad que Agustín tiene en mente al realizar ese tipo de observaciones en torno a una distinción meramente funcional es más estrecha que el tipo de unidad que encontramos en Aristóteles. Para aclarar esto conviene dirigir la mirada desde el centro del libro XII del De Trinitate, donde se encuentran los textos que hasta aquí hemos citado, hacia el comienzo del mismo libro. Pues ahí Agustín menciona que «aquella parte de nosotros que en la acción usa de las cosas corporales y temporales de un modo tal que no nos es común con los animales, ciertamente es racional, pero de aquella sustancia racional de nuestra mente por la que adherimos a la verdad inmutable, pero aquí como derivada a la utilización y al gobierno de las cosas inferiores $»^{40}$. Tal como Adán y Eva son «dos en una carne», escribe Agustín, hay que entender estas formas de la racionalidad como «dos en una mente» ${ }^{41}$. Estas afirmaciones no contienen ambigüedad alguna respecto de la naturaleza fundamentalmente contemplativa de esta mente: es la scientia la derivada. Aristóteles y Agustín pueden estar unidos en lo que esta afirmación tiene de primacía de lo contemplativo, pero se diferencian en que Aristóteles en ningún caso hablaría de la phronêsis como derivada de la sophia. Para Aristóteles son, por decirlo así, ambas originarias. Pero más relevante que la constatación de esta diferencia es el hecho de que la originaria unidad que según Agustín tienen scientia y sapientia constituye el fundamento para una serie de relaciones entre ambas, relaciones que se mantienen también una vez que la scientia ha sido «derivada» a la acción. Estas relaciones constituyen en gran medida la originalidad de la posición agustiniana.

Los objetos de la sapientia, nos dice Agustín, son tan accesibles a la mente como los objetos sensibles para el sentido. No obstante, pocos logran contemplarlos con la mirada de la mente (mentis acies), e incluso

tura, a través del de anima de Tertuliano, el cual Agustín sin duda alguna conoce al escribir el De Trinitate, y en el cual se contiene, bajo expresa referencia a Aristóteles, una crítica de la idea de partes del alma, optando en lugar de ello por hablar de distintas vires et efficaciae [¿traducción de energeiai?] et operae del alma. de an. 14, 3. ed Waszink.

40 trin. XII, 4, 4.

41 trin. XII, 4, 4. Siguiendo tal imagen, el libro XII contiene múltiples referencias a la caída como fornicación, así por ejemplo en XII, 9, 14 y 10, 15. Tras eso se encuentra no sólo la imagen bíblica de la increencia y el pecado como infidelidad, sino que la imagen de la fornicación tiene un particular peso sistemático en trin. XII como contraparte del quoddam rationale coniugium que se busca establecer entre scientia y sapientia (XII, 12, 19). 
aquellos que pueden, lo logran sólo por un breve instante ${ }^{42}:$ «Cuando alguien lo logra, en tanto es posible, tampoco él puede permanecer ahí, sino que es como repelido por el reverberar de la mirada misma (veluti acies ipsa reverberata repellitur), y nos quedamos así sólo con un pensamiento pasajero de una realidad no pasajera» ${ }^{43}$. Hay aquí, tal como en el texto del de ordine que antes hemos citado, un claro paralelo con el libro VII de La República de Platón, pero esta vez en lo que se refiere a la parcial ceguera sufrida al salir de la caverna. Si bien Platón parece considerar como posible la idea de un acostumbramiento de la vista a la luz ${ }^{44}$, también él obliga al que ha completado el ascenso a volver a la caverna ${ }^{45}$. Pero ni en Platón ni en Agustín esto se traduce en una pérdida de lo contemplado. En Platón el regreso a la caverna tiene por objeto precisamente que lo ganado en la contemplación sea ahora afianzado en el mundo perecible de las cosas humanas. ¿Y en Agustín? Tampoco aquí lo contemplado se pierde, sino que es conservado en la memoria «para que exista un lugar al que pueda volver el pensamiento que fue obligado a transitar [de regreso] $\rangle^{46}$. Dicha vuelta a lo antes contemplado, explica Agustín, es para rumiar sobre ello (quodammodo ruminare), y así transformarlo en una disciplina (in disciplinam traicere $)^{47}$. Pero disciplina es un término que precisamente entre los libros XII y XIV del De Trinitate es usado como sinónimo de scientia $^{48}$ : el rumiar sobre lo contemplado por la sapientia es uno de los modos en que se constituye pues la scientia, y así se opera un afianzamiento de lo contemplado no sólo -como en Platón- en el mundo empírico, sino también en una segunda forma de conocimiento.

Observemos a continuación esta relación entre scientia y sapientia desde el ángulo inverso, el del actuar de la sapientia sobre la scientia. La sapientia es mencionada en más de un texto agustiniano como regula ${ }^{49}$. Pero éste no es el único sentido en que ella se relaciona con la práctica. La descripción de la caída, que es uno de los temas principales de De Trinitate XII, sitúa a

\footnotetext{
42 Véase la similar descripción que Agustín hace de la visión de Ostia en conf. IX, 10, 24.

43 trin. XII, 14, 23.

44 rep. 516a-b.

45 rep. 519d.

46 trin. XII, 14, 23.

47 trin. XII, 14, 23.

48 trin. XII, 14, 22 scientia sive disciplina. Cfr. también trin. XVI, 1, 1.

49 Cfr. lib. arb. II, 10, 29, un texto agustiniano que muchos escolásticos aducirán en sus discusiones sobre la sindéresis.
} 
la sapientia como propiamente involucrada en nuestro caer, no sólo como aquello que debería haber sido tenido en mente para no caer, esto es, no sólo como regla. Tal como la mujer debe usar un velo (prosigue la interpretación alegórica de Agustín), por el cual no se niega su condición de imagen de Dios, sino que se afirma su necesidad de ser vigilada, asimismo la scientia requiere de cierto velamentum. Es la scientia la que es descrita por Agustín como un saber que guía la acción, pero es a la sapientia a la que se atribuye la función de vigilar, de vigilar precisamente sobre la scientia. Pues puede haber pecados consistentes sólo en un juego mental en torno a la posibilidad de pecar, y en esos pecados sólo está implicada la scientia. Pero para llegar a una obra externa no basta con la participación de la scientia, sino que Agustín afirma que esto se produce cuando la scientia se extiende demasiado hacia las cosas exteriores «con el consentimiento de su cabeza», esto es, con el consentimiento de la sapientia ${ }^{50}$. No obstante haber descrito la scientia como el conocimiento práctico, es sólo por el consentimiento que a ésta da la sapientia -en un acto que bien puede ser comprendido como un acto de la conciencia- que Agustín considera posible la realización de una obra externa. Así es como describe la capacidad ejecutiva (summa potestas membra in opus movendi) como algo propio de la sapientia ${ }^{51}$. Y así, si la antropología temprana de Agustín lo llevaba a una exposición de la tentación que hacía girar todo en torno a un conflicto entre razón y apetito, el foco central del conflicto parece haberse aquí reorientado hacia dentro de la razón.

No resulta finalmente difícil reducir estas relaciones entre scientia y sapientia a un esquema. La scientia se constituye en parte por nuestra experiencia práctica, en parte por la $\mathrm{fe}^{52}$, pero en parte también por un rumiar, por una elaboración de lo contemplado por la sapientia, y no puede realizar ninguna acción externa mala sin consentimiento de la misma. La primariamente contemplativa sapientia se comporta de modo práctico respecto de la scientia, y la primariamente práctica scientia se comporta de modo contemplativo respecto de la sapientia. Con todo lo que se había aproximado a Aristóteles en el hecho de distinguir dos formas de conocimiento fundamentalmente distintas, reaparece aquí un inconfundible elemento integrador platónico.

50 trin. XII, 8, 13.

51 trin. XII, 12, 17.

52 El vínculo de la scientia con la fe es sobre todo objeto de los primeros capítulos del libro XIII. 
Esta caracterización que hemos hecho de la concepción de racionalidad práctica desarrollada por san Agustín en el libro XII del De Trinitate tiene momentos de tono muy distinto. Por una parte hemos visto un momento en que habla de la racionalidad práctica, scientia, como un mero derivado de la sapientia. Es esta sapientia la que es calificada como sustancia contemplativa de la mente, con lo que la racionalidad práctica parece quedar bajo el doble epíteto de insustancial y derivada. Pero la más compleja elaboración posterior nos muestra que también la «sustancia» de la mente, la sapientia, se encuentra involucrada en la acción, tanto así que no hay concreción en una obra externa sin participación de la sabiduría. Estos distintos elementos pueden, de hecho, ser en parte explicados como distintos momentos de la argumentación de Agustín: es precisamente durante la redacción del libro XII que la obra fue robada por sus impacientes discípulos, llevando a una interrupción de al menos dos años ${ }^{53}$. Tras dicha interrupción hay cambios que saltan a la vista, fortaleciendo el perfil de una racionalidad específicamente práctica ${ }^{54}$. Pero esta observación sobre el proceso de redacción de la obra nos lleva a la difícil pregunta por el lugar de scientia y sapientia en el proyecto del De Trinitate.

\section{$V$. Scientia y sapientia en el proyecto de De Trinitate}

Hasta aquí hemos ofrecido una interpretación de scientia y sapientia que se aleja de la comprensión predominante que reina sobre estas formas de conocimiento. Con ello, sin embargo, no se ha dicho aún nada sobre el lugar que ocupa esta doctrina dentro del conjunto de la exploración agustiniana sobre la Trinidad y su imagen en el hombre: ¿cómo se vincula una disquisición sobre la relación entre el saber práctico y el contemplativo con el esfuerzo de ascensión e interiorización desarrollado por Agustín en la búsqueda de estructuras trinas que puedan ser calificadas de imagen de Dios? Tal pregunta es difícil de responder, pero no es la única parte del De Trinitate en que nos vemos enfrentados a una dificultad de este

53 Para la cronología de la redacción de la obra véase R. KANY, Augustins Trinitätsdenken. Bilanz, Kritik und Weiterführung der modernen Forschung zu De Trinitate (Mohr Siebeck, Tübingen, 2007) 31-46.

54 Nótese, por ejemplo, que recién en trin. XII, 14, 22 -esto es, en el párrafo con el que retoma el trabajo- Agustín intenta ofrecer una fundamentación bíblica para la distinción entre formas de conocimiento. Para el papel desempeñado en esta cuestión por las citas bíblicas cfr. M. Marin, «Note su philosophia e sapientia in Agostino», Vetera Christianorum 27 (1990). 
tipo. Se trata, después de todo, de una obra llena de excursos (o aparentes excursos). En algunos casos la presencia de los mismos puede ser explicada como una exercitatio animae, un entrenamiento de la razón destinado a purificarla, de ese modo preparándola para los siguientes pasos en la exploración trinitaria $a^{55}$. Pero la discusión sobre scientia y sapientia, que se extiende desde el comienzo del libro XII hasta el final del libro XIV es más que un excurso. ¿Cómo se vincula esta larga sección con los restantes temas de la obra y con la estructura de la misma?

Intentar una respuesta a dicha pregunta excede el fin del presente artículo. Pero es posible al menos hacer algunas indicaciones sobre cómo la incomprensión de la verdadera naturaleza de scientia-sapientia ha dificultado hasta aquí el análisis de la estructura de la obra, y hacer alguna observación sobre cómo se puede avanzar una vez aclarado este punto. Tal como en el caso de cualquier obra genial, la pregunta por su estructura es decisiva para su recta comprensión, y así no es de extrañar que durante las últimas décadas haya habido varios intentos por explicarla mejor. Común a dichos intentos es el rechazo del modelo según el cual los primeros siete libros representarían la explicación dogmática -sobre todo en términos de prueba escritural- de la Trinidad y los siguientes ocho el intento por comprensión filosófica, como si el método de una fides quaerens intellectum coincidiera con el orden de los libros del De Trinitate. Después de todo, partes importantes de la primera mitad de la obra son de un marcado esfuerzo por comprensión racional ${ }^{56}$. Y la segunda parte de la obra, lejos de consistir en un simple intento por comprensión racional de lo establecido en la primera mitad, intenta introducir en un nuevo tipo de pensamiento trinitario. La segunda mitad de la obra, iniciada con el libro VIII, parte con la pregunta por la posibilidad de decir algo sobre la Trinidad a partir de la contemplación de los conceptos de verdad, bien y justicia, ascendiendo desde ellos a la verdad misma, la bondad misma y la justicia misma que es Dios ${ }^{57}$. Aunque esta visión es considerada por san Agustín como posible, es deficiente en

55 La discusión sobre el sentido en que la obra tiene como objetivo fundamental la purificación se extiende desde Henri-Irénée, Marrou. Augustin et la fin de la culture antique (Paris, 1958).

56 Revisión crítica de las distintas propuestas de estructuración en R. KanY, Augustins Trinitätsdenken, 181-190.

57 trin. VIII, 2, 3; VIII, 3, 4 y VIII, 9, 13. 
cuanto estos atributos son determinaciones ad se y no ad aliquid relative ${ }^{58}$ : nos dicen algo sobre Dios, pero no en cuanto trino, pues no dicen nada sobre diferencias relacionales. Es el cierre de esta puerta, por decirlo así, lo que abre el camino a un intento por entonces ver al menos per speculum, mediante la exploración de distintas estructuras trinitarias en la imagen de Dios, el hombre, objeto de los libros que siguen. Dentro de dicha búsqueda el paso del libro XI al libro XII constituye un paso hacia el hombre interior. Se trata pues aquí de buscar estructuras trinitarias en un campo específicamente humano. Es eso lo que lleva al comienzo del libro XII a una aclaración de lo que constituye lo específicamente humano ${ }^{59}$, al mismo tiempo dividiendo dicha realidad específicamente humana en dos partes, de las cuales una se ocupa de la administración de lo temporal y la otra de la contemplación de lo eterno.

Pero aquí se vuelve entonces fundamental entender la distinción entre formas de conocimiento del modo que la hemos expuesto, pues si la scientia es entendida como un saber respecto del mundo natural, naturalmente resulta difícil ver cómo la discusión sobre ella puede ser integrada -y como es integrado todo el libro XII- en el plan de la obra. Así, un estudio de Edmund Hill sobre la estructura del De Trinitate que intenta una acabada exposición de la unidad sistemática de la obra, sólo sabe decir respecto del libro XII que éste trata sobre «la caída del hombre» ${ }^{60}$. Un reciente libro sobre Felicidady Trinidad a la luz del $<$ De Trinitate $>$ de san Agustín da sobrada cuenta de la pervivencia de tal incapacidad para ver lo que está en discusión. Pues en este caso el tema mismo de la monografía en cuestión debería haber abierto la mirada a la detallada discusión del libro XII sobre el tipo de conocimiento que requerimos para la felicidad. Pero esto no ocurre, sino que de principio a cabo el autor habla de «ciencia» y sabiduría, pasando por lo mismo por alto decisivos aportes de san Agustín ${ }^{61}$. La contribución que más decisivamente corrige esta tendencia -esto es, la única publicación sobre la estructura de la obra en que la discusión

58 Para esta distinción cfr. trin. V, 8, 9.

59 trin. XII, 3, 3. ut non sit nobis commune cum pecore.

${ }^{6}$ E. Hill, «St Augustine's De Trinitate. The Doctrinal Significance of its Structure», Revue des études angustiniennes, 19 (1973) 383.

61 E. Brotóns Tena, Felicidad y Trinidad a la luz del $<$ De Trinitate $>$ de san Agustín (Secretariado Trinitario, Salamanca, 2002). De las páginas 111 a 118 el autor discute la relación de esta «ciencia» con la sabiduría. En las páginas 286-297 el tema es «conocer para ser feliz», y el autor no realiza referencia alguna al libro XII. 
sobre scientia y sapientia desempeña algún papel- es un artículo de Lewis Ayres sobre el contexto cristológico del libro XIII ${ }^{62}$. Ayres sí ofrece una discusión detallada de la relación entre scientia y sapientia, pero sobre todo a partir de la unidad de las mismas en Cristo, y a partir de los paralelos entre estos pasajes cristológicos del libro XIII y la previa discusión cristológica del libro IV. Pero una vez más resulta llamativo que tal esfuerzo sea sin recurso alguno al libro XII, tal vez un indicio más de la dificultad de dar una interpretación de esta obra que integre la teología y la filosofía en el modo propio de Agustín.

Pues en medio del esfuerzo ascencional y de interiorización ${ }^{63}$ de estos libros la filosofía y la fe interactúan de modo muy significativo. Esto puede ser constatado en distintos niveles. En primer lugar, si miramos las fuentes de Agustín. Cuando años tras el hurto retoma la redacción de la obra en trin. XII, 14, 22, se produce en dicho párrafo una fructífera combinación de textos de la primera carta a los Corintios y del libro de Job, combinación que da un mayor sustento bíblico a lo que en los párrafos precedentes venía explicando; una similar unión de textos bíblicos relevantes se encuentra en otro párrafo central para la distinción y unión entre las formas de conocimiento, trin. XIII, 19, 24, esta vez fundamentalmente a partir de Colosenses y el evangelio de Juan. Pero al mismo tiempo que notamos la creciente fundamentación bíblica de la distinción entre las formas de conocimiento, conviene notar que precisamente éstos son los primeros libros del De Trinitate en que la filosofía pagana se encuentra notoriamente presente a nivel textual y argumentativo ${ }^{64}$ : un número importante de los fragmentos conservados del Hortensius ciceroniano proviene de estos libros, en los que además se trata sobre el fracaso de un filosofar sine mediatore ${ }^{65}$ (una clásica tesis de Agustín contra el platonismo pagano).

62 L. Ayres, «The Christological Context of Augustine's De Trinitate XIII: Toward Relocating Books VIII-XV», Augustinian Studies, 29 (1998).

63 trin. XIV, 3, 5. ab inferioribus ad superiora ascendentes vel ab exterioribus ad interiora ingredientes.

${ }^{64}$ Platón se encuentra representado en los primeros doce libros mediante una única cita, en trin. IV, 18, 24.

65 Los años de interrupción del De Trinitate son años en parte dedicados a la redacción de De Civitate, lo cual explica la renovada familiaridad con textos paganos. Al respecto cfr. H. Hagendahl, Augustine and the Latin Classics, vol.2 Augustine's Attitude (Acta Universitatis Gothoburgensis, Göteborg, 1967) 451. La presencia de estas citas ha llevado a Goulven Madec a aventurar la idea de que la distinción entre scientia y sapientia provendría del mismo Cicerón, dada la doble función de contemplación y 
Pero por sobre lo textual deben ser mencionados los problemas de fondo que en estos libros vinculan la fe y la especulación filosófica. El libro XII es un libro sobre las formas de conocimiento, pero también sobre la imagen de Dios y, particularmente, sobre su pérdida en la caída ${ }^{66}$. El hecho de tener presente el vínculo entre las consecuencias morales y epistemológicas de la caída lleva a Agustín a varios de sus énfasis más característicos, como la crítica de la «scientia que infla». Los dos párrafos del libro XII en que Agustín evoca estas palabras de I Cor 8,1 son precisamente párrafos que en gran medida buscan resumir el núcleo de su posición ${ }^{67}$. El libro XIII, en tanto, es un libro sobre el ansia universal de felicidad, pero al mismo tiempo es el libro de la obra que más se detiene en la necesidad de fe, y el que -junto al libro IV-contiene la principal discusión sobre la encarnación. Lo que en este libro escribe Agustín sobre scientia y sapientia es siempre a propósito de Cristo, sobre la vanidad del filosofar sin mediador: situadas las secciones sobre scientia y sapientia al comienzo y al final del libro, envuelven las restantes preocupaciones vitales del libro XIII ${ }^{68}$. La indagación específicamente trinitaria parece retroceder en estos libros, pero no es porque Agustín pierda el rumbo distraído por un tema ajeno, sino por las dificultades implicadas en dar cuenta adecuadamente de la caída y de la necesidad de reforma de la imagen para alcanzar sabiduría ${ }^{69}$. Un esfuerzo de esa naturaleza lleva a la amplia tematización de las relaciones entre lo teórico y lo práctico, y por tanto no puede ser entendido a cabalidad si se deja de lado el libro XII.

fomento de las virtudes con que la sabiduría es vinculada en diversos fragmentos del Hortensius. Pero la novedad de la posición agustiniana desde luego no consiste en la trivial afirmación de que la sabiduría incluya dichas dos preocupaciones. Dicha posición es más bien la del Agustín temprano, posición precisamente superada por la mayor diferenciación de los libros del De Trinitate que aquí discutimos. Cfr. G. Madec, «L' Hortensius de Cicéron dans les livres XIII-XIV du De Trinitate», Revue des études angustiniennes, 15 (1969) 167-173.

66 Para el análisis de la pérdida de la imagen cfr. trin. XII, 8, 13- 12, 19.

67 trin. XII, 11, 16 y XII, 14, 21-22.

68 Los pasajes relevantes son trin. XIII, 1, 1-4 y 19, 24-20, 26. Entre dichos pasajes es que se trata sobre la fe y la necesidad de mediación. Considero que XIII, 19, 24 es el párrafo que en este sentido mejor sintetiza las diversas preocupaciones del libro.

69 $\mathrm{Al}$ respecto hay acertadas observaciones en L. GIOIA, The Theological Epistemology of Augustine's De Trinitate (Oxford University Press, Oxford, 2008) 219-231, aunque su comprensión de la scientia como science hace perder intensidad a sus resultados. 
Volviendo al comienzo de dicho libro, conviene notar que Agustín afirma ya desde los primeros apartados que en estos dos lados de lo específicamente humano, la scientia y la sapientia, hay una trinidad, pero que sólo en la trinidad propia de la sapientia estamos ante una trinidad que es además imagen del Dios trino ${ }^{70}$. Tal afirmación se encuentra vinculada a la forma en que Agustín ha expuesto estas formas de conocimiento a partir de la imagen de la diferenciación sexual. Pues esto lo lleva a lidiar con I Cor 11, donde san Pablo parece restringir la imagen de Dios al hombre, en cuanto sólo a éste se le impide cubrir su cabeza por ser imagen de Dios $^{71}$. De Trinitate XII puede en gran medida ser leído como un intento por leer dicho pasaje de san Pablo de un modo que sea compatible con el hecho de que es en la mente racional (rationalis mens), donde no hay diferenciación sexual (ubi sexus nullus est), que se encuentra la imagen de $\operatorname{Dios}^{72}$. Pero aquello que la mujer representa en la alegoría, la racionalidad «derivada» hacia la administración de lo temporal, eso no es imagen del mismo $^{73}$. Pero esto sólo rige respecto de esta racionalidad en cuanto es derivada; en cuanto unida a la sapientia es imagen de Dios. Un constante espíritu de tensión mantiene así unida la obra: así como se afirma que la scientia sólo alcanza la imagen de Dios en cuanto está unida a la sapientia e integrada en el amor a lo eterno propio de ésta, también la imagen de Dios que se encuentra en la sapientia está sometida a una condición: que tal imagen sólo se conserva en dirección hacia aquél que la imprimió (non custoditur nisi ad ipsum a quo imprimitur) ${ }^{74}$. Tal tipo de tensión no sólo es característica de modo general del pensamiento de Agustín -el célebre corazón inquieto ${ }^{75}-$, sino que es una tensión que una y otra vez es vinculada por el hiponense con la humanidad y divinidad de Cristo, quien es medicina y médico a la vez, via y patria ${ }^{76}$. Es con ese tipo de énfasis que

70 trin. XII, 4, 4.

71 trin. XII, 7, 9.

72 trin. XII, 7, 12.

73 trin. XII, 7, 12. ut non maneat imago dei nisi ex qua parte mens hominis aeternis rationibus conspiciendis vel consulendis adhaerescit. Al respecto véase J.T. BAVEL, "Woman as the Image of God in Augustine's <De Trinitate XII>» en A. Zumkeller Signum Pietatis. Festgabe für Cornelius Petrus Mayer (Würzburg, 1989).

74 trin. XII, 11, 16.

75 conf. I, 1, 1.

76 Ese tipo de expresiones son características de textos que se relacionan con nuestra purificación o con la reformatio de la imagen de Dios en nosotros. Véase, a parte de los textos de trin. que discutimos, doctr. chr. I, 14, 13. 
aparece también en De Trinitate la unidad de scientia y sapientia en Cristo: que mediante Él vamos hacia É $\mathbf{l}^{77}$. Resulta así de crucial importancia no entender la relación entre scientia y sapientia como dos etapas de desarrollo espiritual, como ordenadas conforme a una escala ascensional de modo que una de las dos sea alguna vez en esta vida dejada atrás: tendimus per scientiam ad sapientiam, y esa tensión nos caracteriza, para volver a las palabras de las Confesiones, donec requiescam in te ${ }^{78}$.

¿Pero en qué consisten las trinidades que Agustín encuentra en la scientia y la sapientia? Como suele ser usual, la respuesta a ese tipo de pregunta puede parecer decepcionante, pues olvidamos que sólo conocemos en parte, como por espejo. En efecto, en la conclusión del libro XIII Agustín parte por recalcar el carácter de exercitatio animae que han tenido los libros XII y XIII, y sus palabras son elocuentes respecto del límite que reconoce: «Quisimos ascender como por grados en las dos formas de saber, buscando, tal como antes la habíamos buscado en el hombre exterior, ahora en el hombre interior una trinidad sui generis en cada forma de conocimiento. Esto para llegar a ver a aquella Trinidad que es Dios, en nuestro limitado modo (pro nostro modulo), si de esto siquiera somos capaces, al menos en enigma y por espejo, por una mente más ejercitada en estas cosas inferiores» ${ }^{79}$. Siendo el libro XIII un libro sobre la fe, y visto el vínculo entre scientia y fe que ofrecen estos dos libros, es natural que las observaciones finales sobre la trinidad propia de la scientia partan de una recollectio de la fe. Si alguien recuerda cualesquiera nociones propias de la fe (ex hac fide et tali vita quaecumque notiones $)^{80}$, y entiende las palabras que está recordando y las ama, y por ese amor vive conforme a ellas -pues cada uno vive según aquello que ama ${ }^{81}$, , esto constituye una trinidad del hombre interior. Por qué dicha trinidad del hombre interior no es aún imagen de Dios es algo que Agustín afirma quedará claro recién cuando se haya comprendido dónde sí se encuentra tal imagen. Que no se encuentre una

77 trin. XII, 19, 24. scientia ergo nostra Christus est, sapientia quoque nostra idem Christus est. ipse nobis fidem de rebus temporalibus inserit; ipse de sempiternis exhibet veritatem. per ipsum pergimus ad ipsum, tendimus per scientiam ad sapientiam.

78 conf. I, $1,1$.

79 trin. XIII, 20, 26.

80 trin. XIII, 20, 26.

81 trin. XIII, 20, 26. cum autem vera esse creduntur et quae ibi diligenda sunt diliguntur, iam secundum trinitatem interioris hominis vivitur; secundum hoc enim vivit quisque quod diligit. 
trinidad que sea imagen de Dios en la vida de la fe se relaciona con la tensión expresada por san Pablo al decir que andamos por fe, no por visión (II Cor 5,7). Pero tal fe pasará, y la imagen de Dios no reside entre las cosas que pasan ${ }^{82}$.

Al hablar luego en el libro XIV sobre aquella trinidad que hay en la sapientia, que además de trinidad es también imagen de Dios, inicia la discusión afirmando que aunque deformada y «desgastada» (obsoleta) por haber dejado de participar de Dios, la imagen de Dios sin embargo permane$\mathrm{ce}^{83}$. La aclaración viene al caso, pues precisamente en el libro XII, en la descripción de la caída que da lugar a una scientia autónoma respecto de la sapientia-que quiere gobernar sola, in potestatem sui, llevando una existencia de carácter experimental ${ }^{84}$-, había afirmado que en ese proceso la imagen de Dios deviene en imagen de bestias ${ }^{85}$. Afirma ahora que el hombre es imagen de Dios precisamente por ser capaz de él y por poder participar del mismo ${ }^{86}$. Pero el espejo tiene que ser reformado, y los libros XII y XIII del De Trinitate tienen recursos aún insuficientemente explotados respecto de la recíproca implicación de aspectos morales y cognoscitivos en dicha reforma, que está lejos de ser reducible a un camino de interiorización y ascensión ${ }^{87}$.

\section{Conclusión: scientia, sapientia y la estructura del pensamiento de san Agustín}

Lo aquí dicho sobre la estructura del De Trinitate consiste más en planteamiento de cuestiones que en su efectivo desarrollo. Pero es mi parecer que su efectivo desarrollo se vuelve mucho más posible una vez entendido el verdadero significado de la distinción entre scientia y sapientia. Pero la comprensión de este binomio no sólo debiera abrirnos el camino a una mejor comprensión de ciertos aspectos del De Trinitate, sino que también es importante de un modo más general para la comprensión del desarrollo intelectual de san Agustín.

82 trin. XIV, 2, $4-3,5$.

83 trin. XIV, 8, 11.

84 Véase XII, 11, 16 para la descripción del experimentum medietatis: la caída desde lo más alto a lo más bajo necesariamente pasa por relacionarnos con nosotros mismos como centro.

85 trin. XII, 11, 16.

86 trin. XIV, 8, 11.

87 Hay acertadas observaciones sobre este punto en A. K. SQUIRE. «Personal Integration in the latter books of Augustine's De Trinitate», Studia patristica, 16 (1985) 564-569. 
En efecto, el hecho de que san Agustín llegara en sus últimos años a desarrollar esta distinción -en medio del conflicto antipelagiano y en medio de una obra sobre la Trinidad- es un indicio de la continuidad de sus preocupaciones filosóficas a la vez que de la radical revisión a la que dichas preocupaciones se ven sometidas por la presión ejercida por una cada vez más acentuada comprensión de la fe cristiana. Pero en este como en tantos otros puntos sería un error entender dicha revisión como un simple quiebre con la tradición filosófica previa. Agustín es movido no a un quiebre, sino a una versión más diferenciada -a la vez que más integradora- de su visión de la sabiduría. Pero el germen de esta madura concepción sobre scientia y sapientia ya estaba en Agustín desde hacía mucho tiempo, como se hace evidente, por ejemplo, a partir de los paralelos estructurales que posee la distinción scientia-sapientia con la distinción entre uti y frui ${ }^{88}$. Y la concepción platónica de orden del alma que dicha temprana distinción representa, es un elemento tan fundacional para la tradición filosófica occidental como lo es la concepción aristotélica de la racionalidad práctica con la cual la posición de Agustín, como aquí ha sido interpretada, parece ser en gran medida compatible.

Por lo que respecta a la visión que el propio san Agustín tiene sobre la novedad de lo cristiano respecto de la filosofía pagana, ella entronca en gran medida con la interpretación que hemos ofrecido aquí. Si dirigimos la mirada al célebre pasaje sobre la lectura de los libri platonicorum en Confesiones VII, uno de los elementos que sobresalen es el hecho de que los platónicos sabían adónde hay que ir, pero no conocían el camino ${ }^{89}$. Puesto en palabras del De Trinitate, se podría decir que tenían un atisbo de sapientia, pero no de scientia. Pero ésa sería una tesis extraña. Sabemos que no sólo tuvieron ambos tipos de conocimiento, sino que concibieron también la posibilidad de su separación. Lo que no tuvieron es alguien que como Agustín los distinguiera manteniendo tal cantidad de relaciones recíprocas entre ambos.

88 Desarrollo dicho punto con mayor extensión en M. Svensson, Theorie und Praxis bei Augustin. Eine Verbältnisbestimmung (Alber Verlag, Freiburg, 2009).

89 conf. VII, 20, 26. videntes quo eundum sit nec videntes qua. 
Resumen: el artículo ofrece una revisión de la distinción entre scientia y sapientia desarrollada en el libro XII del De Trinitate. Se critica aquellas interpretaciones que reducen dicha scientia a conocimiento natural y no práctico, para desde ahí discutir la distinción agustiniana entre las formas de conocimiento en el contexto más amplio de las discusiones antiguas sobre conocimiento práctico y teórico, así como el papel de esta distinción en el contexto de esta obra de san Agustín.

Palabras clave: Agustín, racionalidad práctica, racionalidad teórica, contemplación, acción.

Abstract. The paper offers a revision of the distinction between scientia and sapientia as developed in Book XII of De Trinitate. It reviews the interpretations that reduce said scientia to natural and non practical knowledge, so as to then discuss the Augustian distinction in the broadest context of the ancient discussions on practical and theoretical knowledge, as well as the role of this distinction in the context of such work by St. Augustine.

Key words: Augustine, practical reason, theoretical reason, contemplation, action. 